\title{
CONGENITAL DISLOCATION OF THE HIP
}

\section{Experiences of Early Diagnosis and Treatment}

\author{
T. Hiertonn and U. James, Uppsala, Sweden \\ From the Department of Orthopaedics, Akademiska Sjukhuset, Lippsala
}

Before the campaign for the neonatal diagnosis and treatment of congenital dislocation of the hip, the incidence of this malformation in Sweden was found to be 09 per cent (Severin 1956). By examining infants during their first days of life with regard to laxity of the hips Andrén and von Rosen (1958) and Palmén (1961) found between 2 and 3 per cent of abnormality (preluxatio coxae). This figure obviously was higher than the incidence of established dislocation.

It is of interest to find out if early diagnosis and generously applied treatment can deal with every case which otherwise would present later with a true dislocation. Another question is whether such treatment will also prevent acetabular hypoplasia or other abnormality.

\section{CLINICAL MATERIAL}

During the years 1962-65 11,868 infants were born in the maternity department of Akademiska Sjukhuset, Uppsala. All were examined within the first few days by a paediatric team, particularly with regard to laxity of the hip joint (Ortolani 1937, 1948; Palmén 1961). Atypical clicks as well as any kind of faulty movement of the hip joint were registered, as well as typical Ortolani clicks, telescopic movement and restricted abduction. With this routine 2 per cent or 242 babies, three-quarters of them girls, were referred for orthopaedic examination. This was performed shortly afterwards, mostly on the fourth day after birth. The orthopaedic examiner had the same impression of abnormality in only about half the cases.

Comment-Over these four years we certainly overemphasised atypical clicks, which are easily elicited in newborn infants by manipulation but which do not indicate abnormal joint laxity or potential dislocation.

\section{STANDARD TREATMENT 1962-65}

Almost all babies (231 out of 242 ) in whom the paediatric physician suspected some abnormality had simple abduction treatment by means of a Frejka pillow (Frejka 1941) for about three months.

Comment-The indication for this treatment was mainly based on the findings at the first examination by the paediatric team. The reason for this was that laxity can disappear during the first days of life when the high urinary excretion of oestrogen hormones rapidly diminishes (Andrén 1960; Andrén and Borglin 1961). We were well aware that a great number of these infants were treated for only suspected laxity of the hips. Over-diagnosis and treatment, however, were both accepted in the hope that congenital dislocation of the hip would no longer appear and that normal joints would result in all cases. Treatment with a Frejka pillow is of course very simple for mother and child, and no structural changes of the capital epiphysis have been caused by it.

\section{RESULTS}

After this standard treatment 224 out of 231 infants were assessed as normal and had no further treatment. They were later checked at the children's welfare centre.

Additional treatment-In seven cases the standard Frejka pillow treatment was considered not to be sufficient. In four of these cases the reason was a slight acetabular dysplasia shown in the routine radiograph at the age of three months. After prolonged abduction in plaster all these four patients had satisfactory development of the hip joint.

The remaining three cases ( 1 to 3 ) are of special interest. The reason for additional treatment in these cases was persistent instability as well as radiographic subluxation. 


\section{CASE REPORTS}

Case 1-Girl with right-sided laxity. There was a positive Ortolani sign. A Frejka pillow was worn for two months. The hip was then assessed as normal clinically and radiographically. At the age of seven months there was subluxation with acetabular dysplasia and the capital epiphysis was not visible on the right side. Closed reduction was performed and plaster was applied for seven months, followed by a night-splint for a year.

At the age of five years gait was normal. There was full movement, with increased medial rotation. Radiographs showed bilateral coxa valga and increased anteversion. The acetabula were normal.

Case 2-Boy with right-sided laxity and positive Ortolani sign; and left-sided dislocation with shortening. A Frejka pillow was worn for eight weeks, but the dislocation persisted. Closed reduction was performed and plaster was applied for eight months, followed by a night-splint for six months.

At follow-up at the age of four and a half years gait was normal. There was full hip movement, but increased medial rotation. Radiographs showed bilateral coxa valga and increased anteversion. The acetabula were normal.

Case 3 (atypical)-Boy with arthrogryposis. There were severe deformities of hands and feet. Both hips were dislocated and rigid. Traction and repeated manipulation failed to effect reduction. At fourteen and sixteen months open reductions were performed and prolonged splintage was maintained.

At follow-up at the age of four and a half years movements were satisfactory and radiographically there was good development of the hip on both sides.

Comment-It is obvious that a Frejka pillow is not a satisfactory method of treatment.

\section{CHILDREN CONSIDERED NORMAL. AT BIRTH}

A total of 11,626 children were examined during their first days of life by the paediatric team and assessed as normal. Later-usually after two to four months-twenty-three infants were referred for orthopaedic examination because of suspected abnormality of the hip. Eighteen of these had findings such as crepitation, restricted abduction and asymmetry of the thigh region and received simple abduction treatment.

After looking through the records we believe that there were no potential luxations among these eighteen cases. The abduction treatment was given as a precaution.

Five infants considered normal soon after birth were later referred for orthopaedic examination with established dislocation (Cases 4 to 8 ).

\section{CASE REPORTS}

Case 4-Girl with dislocation of the left hip diagnosed at three months. Closed reduction was performed after subcutaneous adductor tenotomy. A plaster cast was applied for six months and a night-splint for seven months.

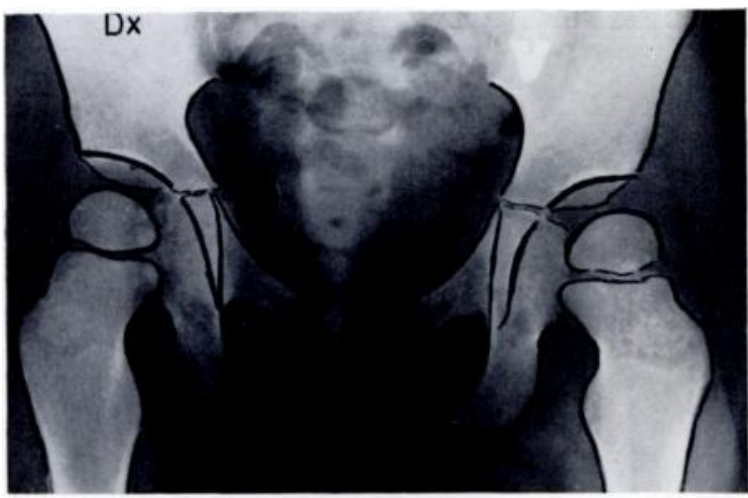

FIG. 1

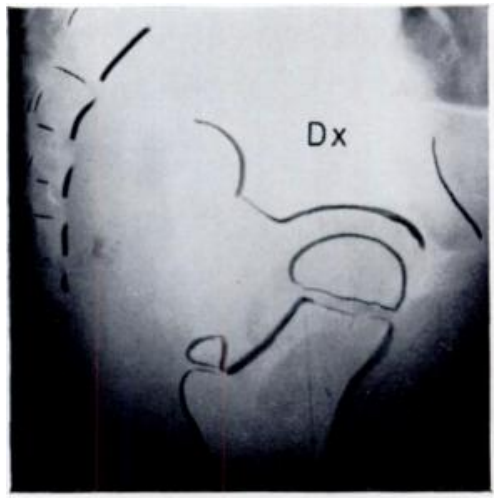

Case 4-Radiograph at age of 3 years. Note the bilateral coxa valga and increased anteversion.

At three years of age there was no limp. The feet were in 10 degrees of medial rotation. Movements were full, with increased medial rotation. Radiographs showed bilateral coxa valga and increased anteversion. The acetabula were normal (Fig. 1). 
Case 5-Girl with dislocation of left hip diagnosed at four months. Treatment was by traction followed by closed reduction and a plaster for six months, with a night-splint for a further six months.

At four years there was no limp. The feet were in neutral rotation. Movements were full, with increased medial rotation. Radiographs showed bilateral coxa valga and increased anteversion. The acetabula were normal.

Case 6-Girl with dislocation of left hip diagnosed at four months. Treatment was by closed reduction and plaster for six months, followed by a night-splint for six months.

At the age of three years there was no limp. The feet were in 10 degrees of medial rotation. Movements were full, with increased medial rotation. Radiographs showed somewhat irregular structure of the left femoral head epiphysis, and increased anteversion. The acetabula were probably normal.

Case 7 (atypical)-Boy with congenital megacolon, operated on neonatally but with continuing intestinal problems. Dislocation of right hip was diagnosed at one year. Treatment was by closed reduction and plaster for six months, followed by a night-splint for a year.

At two and a half years there was no limp. Movements were satisfactory but medial rotation was increased. Radiographs showed on the right side marked acetabular dysplasia, with deformation of the neck and head. On the left side the acetabulum was normal. There was some coxa valga.

Case 8 (atypical)-Boy with intestinal, urinary and skeletal malformations. Diagnosis of bilateral laxity and dislocatable hips at the age of one month. Closed reduction was performed and a plaster was worn for eight months followed by a night-splint for one year. Because of persistent acetabular dysplasia, coxa valga and increased anteversion, a varus-rotation osteotomy was performed on the left side at four and a half years.

At five and a half years gait and movement were satisfactory.

Comment-Of these five cases at least one (Case 8) was atypical and probably another (Case 7). It is evident that a single neonatal examination of the hip is not enough. Thanks to examinations repeated at the children's welfare centre the typical cases of dislocation (Cases 4 to 6) were diagnosed within a few months and by the age of one year all three hip joints were stable. The later development in these three cases was clinically very good but all had signs of increased valgus and anteversion of the neck of the femur. It is interesting that these findings were present in both hips though only one side had been dislocated. It is not yet possible to assess the importance of increased valgus and anteversion angle with regard to the future function of the joint.

\section{DISCUSSION}

Without early treatment we could have expected at least eleven cases of persistent hip dislocation, as the natural incidence in Sweden is calculated to be .09 per cent (Severin 1956). Out of 11,868 children born in the maternity department of our hospital and examined while there for hip laxity we found eight cases (five typical and three atypical) with established dislocation after the neonatal period, only one after the age of six months (Case 7). Over the age of one year none had a persistent dislocation. With the exception of the atypical cases all have shown satisfactory development of the hip joints.

The result so far of the campaign for the neonatal diagnosis of hip laxity and early treatment of actual and potential dislocation is satisfactory. It must be pointed out, however, that much unnecessary splinting has occurred. For every child saved from frank dislocation we probably had fifteen to twenty others splinted. As a possible gain, however, some cases of dysplasia (Wiberg 1939) may have been prevented. Since finding three cases of persistent dislocation despite primary treatment with a Frejka pillow we have preferred the von Rosen abduction splint, which gives safer retention in cases of marked instability. This splint is similar in principle to Barlow's splint (Barlow 1962). Furthermore we warmly recommend repeated examinations of the hips at short intervals.

Recently Finlay, Maudsley and Busfield (1967) stressed the importance of classifying the state of the hip joint neonatally in clear-cut groups as a means of comparing the findings in different centres. In this we fully agree. 


\section{CONCLUSIONS}

1. Out of 11,868 children born in one maternity department and examined neonatally three cases (possibly four) of typical dislocation were missed at the first examination but diagnosed and treated with good results within the following few months.

2. One single neonatal examination of the hip is not sufficient. Repeated examinations during the first weeks and months are essential.

3. Treatment with a Frejka pillow is unsatisfactory. The von Rosen splint is preferable.

4. Following the campaign for neonatal diagnosis and early treatment no case of established dislocation has been encountered after the age of six months.

5. Atypical cases present special problems.

\section{REFERENCES}

Andrén, L. (1960): Instability of the Pubic Symphysis and Congenital Dislocation of the Hip in Newborns. Acta Radiologica, 54, 123.

ANDrén, L., and Borglin, N. E. (1961): Disturbed Urinary Excretion Pattern of Oestrogens in Newborns with Congenital Dislocation of the Hip. Acta Endocrinologica, 37, 423.

Andrén, L., and von Rosen, S. (1958): The Diagnosis of Dislocation of the Hip in Newborns and the Primary Results of Immediate Treatment. Acta Radiologica, 49, 89.

Barlow, T. G. (1962): Early Diagnosis and Treatment of Congenital Dislocation of the Hip. Journal of Bone and Joint Surgery, 44-B, 292.

Finlay, H. V. L., Maudsley, R. H., and Busfield, P. I. (1967): Dislocatable Hip and Dislocated Hip in the Newborn Infant. British Medical Journal, 4, 377.

FrejKA, B. (1941): Präventation der angeborenen Hüftgelenksluxation durch das Abduktionspolster. Wiener medizinische Wochenschrift, 91, 523.

Ortolani, M. (1937): Un segno poco noto e sua importanza per la diagnosi precoce di prelussazione congenita dell'anca. Pediatria, 45, 129.

Ortolani, M. (1948): La Lussazione congenita dell'anca. Bologna: Cappelli.

Palmén, K. (1961): Preluxation of the Hip Joint. Acta Paediatrica, 50, Supplement 129.

SEVERIN, E. (1956): Frekvensen av luxatio coxae congenita och pes equino-varus congenitus i Sverige. Nordisk Medicin, 55, 221.

Wiberg, G. (1939): Studies on Dysplastic Acetabula and Congenital Subluxation of the Hip Joint. Acta Chirurgica Scandinavica, 83, Supplement 58. 